Volume 3, Issue 1, February 2018, Pages: 244, DOI: http://dx.doi.org/10.19082/ah244

\title{
GENETIC EPIDEMIOLOGICAL CHARACTERIZATION OF THE POPULATION OF GHAZAOUET, WILAYA OF TLEMCEN (WEST ALGERIA) BY TYPE 2 DIABETES
}

\author{
Sarra Khater ${ }^{1,2}$, Nafissa Chabni ${ }^{3}$, Djamel Belkhatir ${ }^{1}$, Amaria Aouar ${ }^{1}$, Majda Dali1, Houari Hamdaoui ${ }^{1,2}$, Zakarya \\ Moqaddem $^{1,2}$
}

1: Laboratory for the valorisation of human actions for environmental protection and application in public health Department of Biology, Faculty of Science, Abou-Bekr University Belkaid, Tlemcen

2: Cancer Lab, Faculty of Medicine, Abou-Bekr Belkaid University, Tlemcen

3: Service for epidemiology, University Hospital of Tlemcen sarra1112@yahoo.fr

\section{TYPE OF ARTICLE: CONFERENCE ABSTRACT}

\begin{abstract}
Background: Type 2 diabetes is a chronic disease with many complications and consequences. In Algeria, the prevalence of type 2 diabetes is constantly increasing. The main objective of this work is based on the epidemio-genetic characterization of the population of Ghazaouet (West Algeria) by type 2 diabetes.

Methods: This is a descriptive cross-sectional study of a population of 70 diabetic patients over the age of 40 years at the PH (Public Hospital) in Ghazaouet.

Results: This study found that type 2 diabetes affects subjects aged $62 \pm 8.88$ years for men and $62.55 \pm 10.49$ years for women, and affects more women $(75 \%)$ than men $(25 \%)$. For the sociodemographic level, most diabetics are married (95.6\%), live in single-family homes (78.2\%) and $53.62 \%$ are illiterate. The genetic factor is very present, $69.57 \%$ of diabetics have a family history of type 2 diabetes. In this study, $28.98 \%$ of diabetics come from a consanguineous marriage. Anthropometric measurements show an average BMI $>30(\mathrm{Kg} / \mathrm{m} 2)$. Hypertension is found in $68.18 \%$ of diabetics.

Conclusion: The understanding of epidemiological features and the estimation of the risk of type 2 diabetes is an important step in the development of strategies for the treatment and prevention of this disease in our population and in Algeria.

KEYWORDS: Characterization, Diabetes type 2, Epidemio-genetic, Population of Ghazaouet, West
\end{abstract} Algeria

\footnotetext{
Abstracts of Second International Conference on Health Sciences and Medical Technologies, 10-12 October 2017, Tlemcen, Algeria (ICHSMT-17)

(C) 2018 The Authors. This is an open access article under the terms of the Creative Commons Attribution-NonCommercialNoDerivs License, which permits use and distribution in any medium, provided the original work is properly cited, the use is non-commercial and no modifications or adaptations are made.
} 